\title{
Produção científica em avaliação motora: análise bibliométrica sobre a utilização da Escala de Desenvolvimento Motor
}

\author{
Motor assessment scientific production: bibliometric analysis on the use of \\ the Motor Development Scale
}

Producción científica en evaluación motora: análisis bibliométrico sobre el uso de la Escala de Desarrollo Motor

\section{Ricardo de Almeida Pimenta}

Professor doutor na Universidade Federal Rural do Rio de Janeiro, Seropédica, Rio de Janeiro, Brasil. ricardopimentarp@gmail.com

ORCID - https://orcid.org/0000-0002-2432-1277

\section{Lorenna Walesca de Lima Silva}

Mestranda na Universidade do Estado de Santa Catarina, Florianópolis, Santa Catarina, Brasil. lorennalima1995@gmail.com

ORCID - https://orcid.org/0000-0001-5059-8168

\section{Claudia Daniele Bianco}

Doutoranda na Universidade Federal de Santa Catarina, Florianópolis, Santa Catarina, Brasil cacau.bianco@gmail.com

ORCID - https://orcid.org/0000-0002-3152-6895

\section{Mauricio Camaroto}

Doutorando na Universidade do Estado de Santa Catarina, Florianópolis, Santa Catarina, Brasil. mcamaroto@gmail.com

ORCID - https://orcid.org/0000-0001-7721-2157

\section{Francisco Rosa Neto}

Professor doutor na Universidade do Estado de Santa Catarina, Florianópolis, Santa Catarina, Brasil. franciscorosaneto@terra.com.br ORCID - https://orcid.org/0000-0003-1670-024X

Recebido em 12 outubro 2019

Aprovado em 21 de setembro de 2020

Publicado em 26 de outubro de 2020

\section{RESUMO}

A avaliação motora é essencial para acompanhamento do desenvolvimento infantil. No Brasil, a Escala de Desenvolvimento Motor (EDM) destaca-se como um instrumento de avaliação de crianças de 2 a 11 anos. O estudo teve como objetivo analisar a produção científica relacionada a utilização dessa escala através de uma análise bibliométrica, explorando dados nas publicações, autores e periódicos, com foco em indicadores e impactos científicos. Um total de 53 artigos foram considerados, selecionados nas bases de dados SciELO, SCOPUS, MEDLINE, SPORTDiscus, Web of Science e Portal de Periódicos CAPES. Como resultados, a produção científica aumentou a partir de 2010 e têm alcançado revistas nacionais e internacionais e publicações em três idiomas. As revistas com maior fator de impacto estão na área de medicina e as publicações contemplam profissionais da saúde e da educação. A rede de pesquisas envolve 32 
Universidades com maior concentração em SC e SP. O autor da EDM e seus colaboradores institucionais são os que mais vezes publicaram com a escala. Por fim, os estudos têm focado na avaliação de crianças com transtornos do desenvolvimento ou dificuldades de aprendizagem.

Palavras-chave: Crianças; desenvolvimento infantil; bibliometria.

\section{ABSTRACT}

Motor assessment is essential for monitoring child development. In Brazil, the Motor Development Scale (EDM) stands out as an instrument when evaluating children 2 to 11 years old. The study aimed to analyze the scientific production related to the use of this instrument through a bibliometric analysis exploring data from publications, authors and journals, and focusing on scientific indicators and impacts. A total of 53 articles were considered, selected from the databases: SciELO, SCOPUS, MEDLINE, SPORTDiscus, Web of Science and Portal Capes. Results indicate that the scientific production using this scale has increased since 2010 and have achieved national and international journals and publications in three languages. Journals with the greatest impact factor are in the medicine area and the publications include health and education professionals. The research network involves 32 Universities with greater concentration in the state of "SC" and "SP" - Brazil. The author of EDM and its institutional contributors are the ones that most frequently published with the scale. Finally, studies have focused on assessing children with developmental disorders or learning disabilities.

Keywords: Child; child development; bibliometrics.

\section{RESUMEN}

La evaluación motora es esencial para seguir el desarrollo infantil. En Brasil, la Escala de Desarrollo Motor (EDM) se destaca como un instrumento para evaluar a niños de 2 a 11 años. El estudio tuvo como objetivo analizar la producción científica relacionada con el uso de esta escala a través de un análisis bibliométrico, explorando datos en publicaciones, autores y revistas, enfocándose en indicadores e impactos científicos. Se consideraron un total de 53 artículos, seleccionados de las bases de datos: SciELO, SCOPUS, MEDLINE, SPORTDiscus, Web of Science y Portal CAPES. Como resultado, la producción científica aumentó desde 2010 y ha llegado a revistas y publicaciones nacionales e internacionales en tres idiomas. Las revistas con el mayor factor de impacto pertenecen al campo de la medicina, y las publicaciones incluyen profesionales de la salud y la educación. La red de investigación involucra a 32 universidades con la mayor concentración en "SC" y "SP" Brasil. El autor de EDM y sus colaboradores institucionales son los que más publicaron con la escala. Finalmente, los estudios se han centrado en evaluar a los niños con trastornos del desarrollo o discapacidades de aprendizaje.

Palabras clave: Niño; desarrollo infantil; bibliometría.

\section{Introdução}

A avaliação motora desempenha papel importante no neurodesenvolvimento infantil, especialmente para a identificação de alterações que possam interferir no desenvolvimento 
http://dx.doi.org/10.5902/1984686X41510

global (CAON; RIES 2003; MEDINA-PAPST; MARQUES, 2010; ROSA NETO, 2015), além de obter esclarecimentos sobre estratégias intervencionistas quando necessário.

Instrumentos internacionais são conhecidos e padronizados para avaliação do desenvolvimento motor de crianças em idade escolar e pré-escolar, tais como o Movement Assessment Battery for Children, 2 ${ }^{\mathrm{a}}$ edição (MABC-2) (HENDERSON; SUGDEN; BARNETT, 2007) e o Bruininks-Oseretsky Test of Motor Proficiency, 2 edição (BOT-2) (DEITZ; KARTIN; KOPP, 2007) e a Alberta Infant Motor Scale (AIMS) (PIPER; DARRAH, 1994), utilizando critérios de seleção variados, como a idade da criança e as áreas a serem avaliadas. Entretanto, esses instrumentos apresentam alto custo de compra e importação além de manuais e instruções gerais em língua inglesa. Como alternativa viável a avaliação do desenvolvimento infantil, no Brasil, encontra-se a Escala de Desenvolvimento Motor (EDM) (ROSA NETO, 2015). Essa escala foi desenvolvida com o objetivo de fornecer um instrumento de avaliação do desenvolvimento motor de crianças a partir da idade cronológica, idades motoras e quocientes motores, tendo como objetivo fornecer parâmetros de níveis de desenvolvimento e de identificar crianças com atrasos motores. Esse instrumento abrange uma faixa etária de 2 a 11 anos e avalia três pilares da motricidade humana: coordenação, propriocepção e percepção; e seis domínios específicos: motricidade fina, motricidade global, equilíbrio, esquema corporal, organização espacial e temporal. Em português, a EDM teve sua primeira publicação em 2002 (ROSA NETO, 2002) e encontra-se atualmente na terceira edição. Em espanhol (ROSA NETO, 2018a) e inglês (ROSA NETO, 2018b), edições publicadas em 2018.

A utilização do protocolo envolve crianças em idade pré-escolar (2 a 5 anos), do ensino fundamental ( 6 a 11) e da educação especial. A Escala EDM vem sendo utilizada para diagnóstico diferencial de transtornos, suspeitas de atrasos no desenvolvimento, complemento de avaliação clínica médica, alterações neurológicas e psiquiátricas, deficiências intelectuais, e outros (ROSA NETO; BIANCO, 2018). No campo científico, a EDM tem sido utilizada na avaliação de crianças com transtornos do desenvolvimento e de aprendizagens, assim como crianças com deficiências ou atrasos cognitivos e/ou motores (GOULARDINS et al., 2013; ROSA NETO et al., 2015; POETA et al., 2011; ROSA NETO, 2013; PAVÃO et al., 2014).

Análises bibliométricas têm sido utilizadas em diferentes contextos para avaliar dados sobre aumento no número de publicações, identificação dos principais autores e instituições envolvidas nas pesquisas, assim como locais e países que investigam um determinado 
http://dx.doi.org/10.5902/1984686X41510

tema (BRAMNESS et al., 2014; ANDRADE; DOMINSKI; COIMBRA, 2017). Em complemento, Hu et al. (2014) apontam que a literatura, de maneira geral, apresenta análises bibliométricas específicas de periódicos visando estabelecer tendências ou direções para pesquisas futuras. Dessa forma, entende-se que maior número de informações sobre instituições, autores e colaboradores, palavras-chave e periódicos devem ser acrescentados em estudos como as análises bibliométricas (ANDRADE; DOMINSKI; COIMBRA, 2017).

Mediante o exposto, este estudo tem como objetivo analisar a literatura especializada acerca da utilização da EDM na avaliação do desenvolvimento motor de crianças. A partir disso, o presente estudo visa apresentar e quantificar informações relevantes referente a utilização da EDM em pesquisas, explorando indicadores bibliométricos relativos à distribuição das publicações ao longo do tempo, periódicos, idioma, temáticas, redes de conexão entre publicações e indicadores de atividades. Explorar essas informações deve respaldar o impacto científico da utilização da escala e apontar tendências ou direções para pesquisas futuras.

\section{Métodos}

\section{Estratégia de busca}

O rastreio dos trabalhos científicos de interesse para esta pesquisa foi feito através de uma busca sistemática na literatura. Representando uma parte significativa da produção científica mundial, a pesquisa pelos artigos foi realizada nas seguintes bases de dados: Scientific Electronic Library Online, SciELO ( $\approx$ 1,285 periódicos e 745,182 artigos), SCOPUS ( $\approx 21.500$ periódicos, de 5 mil editores internacionais), MEDLINE (via PubMed) ( $\approx 5600$ periódicos $\mathrm{e} \approx 21,000,000$ artigos), SPORTDiscus $(\approx 500$ periódicos $)$, Web of Science $(\approx 9.000$ periódicos indexados) e Portal de Periódicos CAPES $(\approx 45,000$ publicações). Os termos de pesquisa utilizados nas bases de dados referem-se, respectivamente, aos nomes do protocolo de avaliação (Escala de Desenvolvimento Motor) e de seu autor (Francisco Rosa Neto). Estes descritores foram combinados com auxílio do operador booleano "OR", da seguinte forma: ("Escala de Desenvolvimento Motor" OR "Motor Development Scale") OR ("Rosa Neto, Francisco" OR “Neto, Francisco Rosa” OR "Rosa Neto, F" OR “Neto, FR" OR “Francisco Rosa Neto"). Essas estratégias foram comuns a todas as bases, com uma busca integrada nos campos title, abstract, subject, author, de cada banco de dados. 
http://dx.doi.org/10.5902/1984686X41510

\section{Critérios de inclusão e exclusão}

Como critérios de inclusão, foram considerados: a) artigos originais em periódicos científicos; b) artigos que utilizaram a Escala de Desenvolvimento Motor; e, c) textos completos publicados em inglês, português ou espanhol. Não houve restrição quanto à data de publicação. Foram excluídos os artigos de revisão, pesquisas que não utilizaram a EDM para a análise do desenvolvimento motor, publicações que não disponibilizam texto completo, trabalhos em revistas não científicas, e os trabalhos publicados em revistas sem classificação para a área 21 do Qualis CAPES, obtidos através da consulta na "Plataforma Sucupira" (https://qualis.capes.gov.br).

Todos os estudos que preencheram os critérios de inclusão foram submetidos à coleta de dados para análise e discussão bibliométrica. As principais características foram sintetizadas de acordo com um modelo de extração de dados constituído por: autor; local da pesquisa; ano de publicação; universidades envolvidas, autores envolvidos, características das revistas e características dos artigos.

\section{Análises}

Os dados foram armazenados e analisados no programa estatístico SPSS versão 20.0. Os resultados são apresentados de forma descritiva com apresentação das frequências e percentuais.

\section{Resultados}

A busca sistemática nas bases de dados retornou um total de 392 estudos. Outros 12 artigos foram adicionados mediante consulta às listas de referências. Ao final das etapas de seleção, elegibilidade e inclusão, um total de 53 artigos preencheram os critérios de inclusão e foram considerados nesta pesquisa, como apresentado na Figura 1. 
http://dx.doi.org/10.5902/1984686X41510

Figura 1 - Fluxograma ilustrando as etapas da revisão de literatura e seleção dos artigos

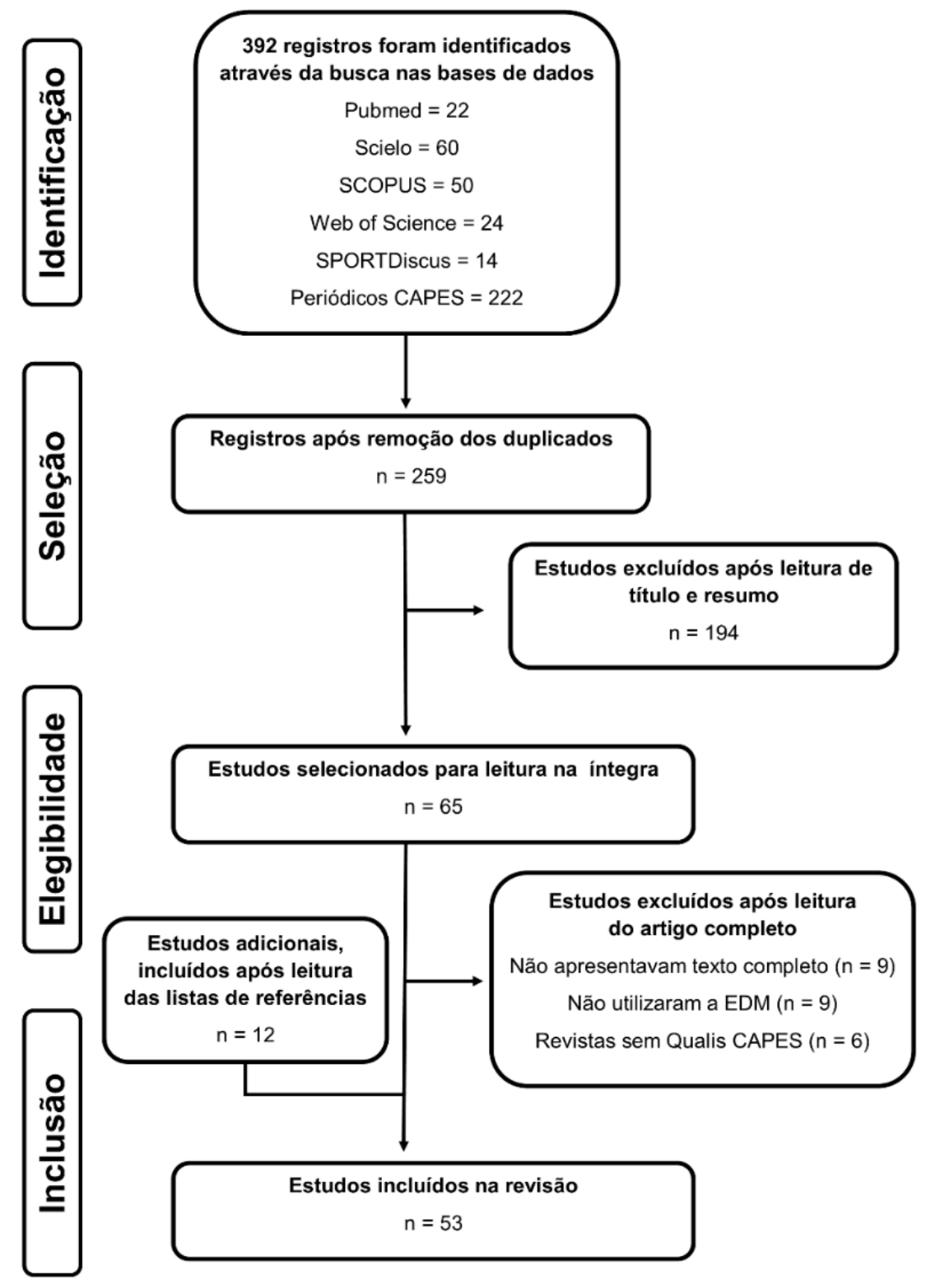

Fonte: Os autores (2019).

\section{Sobre as publicações}

As publicações científicas tiveram início no ano de 2003, um ano após a publicação da primeira versão do Manual de Avaliação Motora e tiveram um crescimento significativo a partir do ano de 2010, com $43(81,1 \%)$ dos artigos publicados nesse período, como apresentado na Figura 2. 
http://dx.doi.org/10.5902/1984686X41510

Figura 2 - Número de publicações por ano

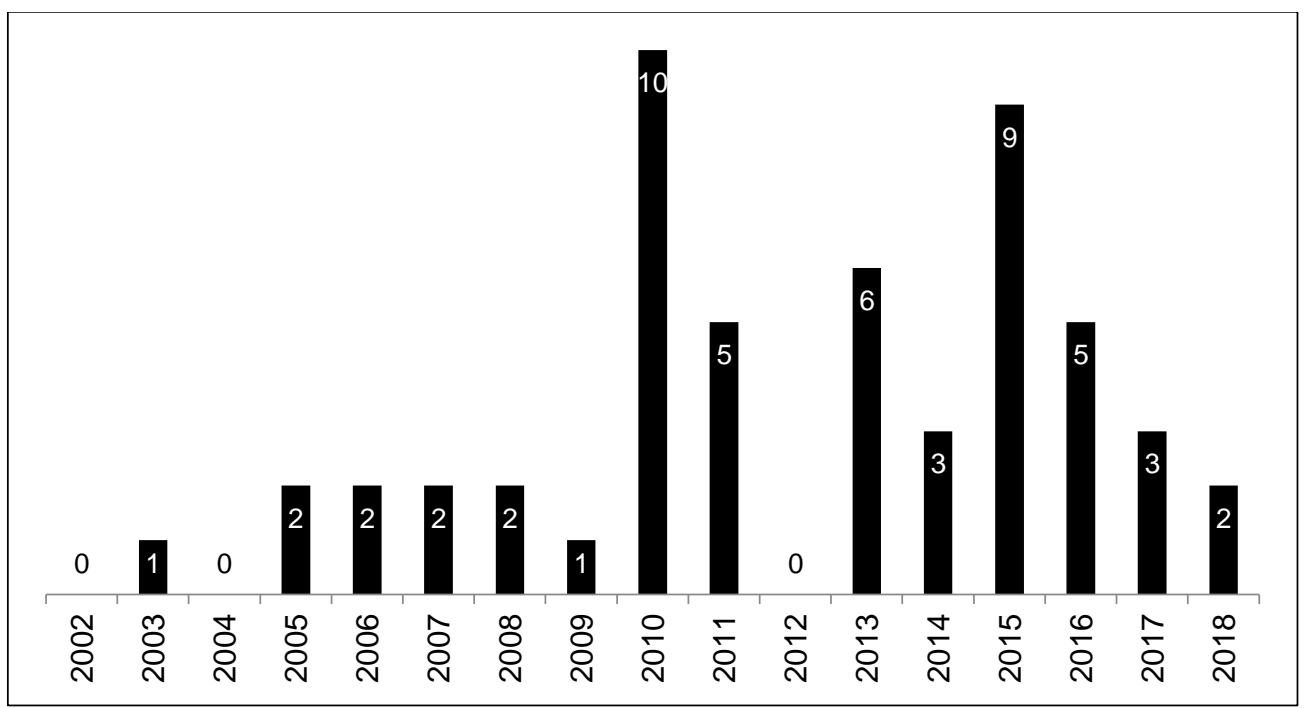

Fonte: Os autores (2019).

Os artigos selecionados para essa revisão bibliométrica estão publicados em 26 revistas científicas diferentes, das quais 12 apresentam fator de impacto e índice $\mathrm{H}$ descritos no Scimago Jounal Rank (SJR). Percebe-se que existe uma prevalência de estudos publicados em revistas brasileiras, com destaque para a área da saúde, como apresentado na Tabela 1.

Tabela 1 - Publicações relativas a EDM: revista, fator de impacto, país e área da revista

\begin{tabular}{|c|c|c|c|c|c|}
\hline REVISTA & SJR & $\begin{array}{l}\text { ÍNDICE } \\
\mathrm{H}^{*}\end{array}$ & PAÍS & ÁREA $^{\dagger}$ & $\mathbf{N}$ \\
\hline $\begin{array}{l}\text { Research in developmental } \\
\text { disabilities }\end{array}$ & 0,90 & 76 & $\begin{array}{l}\text { Reino } \\
\text { Unido }\end{array}$ & Psicologia & 1 \\
\hline $\begin{array}{l}\text { Revista Brasileira de } \\
\text { Psiquiatria }\end{array}$ & 0,80 & 44 & Brasil & Medicina & 1 \\
\hline Revista Paulista de Pediatria & 0,47 & 12 & Brasil & Medicina & 3 \\
\hline $\begin{array}{l}\text { Arquivos de Neuro- } \\
\text { Psiquiatria }\end{array}$ & 0,45 & 42 & Brasil & Medicina & 1 \\
\hline $\begin{array}{l}\text { Rev Bras Cineantropom } \\
\text { Desempenho Hum }\end{array}$ & 0,25 & 17 & Brasil & Fisiologia & 5 \\
\hline $\begin{array}{l}\text { MOTRIZ: Revista de } \\
\text { Educação Física }\end{array}$ & 0,25 & 9 & Brasil & P. em Saúde & 1 \\
\hline $\begin{array}{l}\text { Psicologia Escolar e } \\
\text { Educacional }\end{array}$ & 0,22 & 5 & Brasil & Psicologia & 1 \\
\hline Revista de Neurología & 0,22 & 36 & Espanha & Medicina & 2 \\
\hline $\begin{array}{l}\text { Rev int med cienc act fís } \\
\text { deporte }\end{array}$ & 0,21 & 11 & Espanha & P. em Saúde & 1 \\
\hline Rev bras educ espec & 0,20 & 8 & Brasil & C. Sociais & 8 \\
\hline Motricidade & 0,19 & 8 & Portugal & P. em Saúde & 1 \\
\hline $\begin{array}{l}\text { Journal of Physical } \\
\text { Education }\end{array}$ & 0,19 & 5 & Brasil & Medicina & 4 \\
\hline ABCS Health Sciences & - & - & Brasil & P. em Saúde & 1 \\
\hline
\end{tabular}


http://dx.doi.org/10.5902/1984686X41510

Tabela 1 - Publicações relativas a EDM: revista, fator de impacto, país e área da revista

\begin{tabular}{llllll}
\hline REVISTA & SJR ÍNDICE & PAíS & ÁREA $^{\dagger}$ & N \\
& & H $^{*}$ & & & \\
\hline Cad Bras Ter Ocup & - & - & Brasil & TO & 3 \\
Ciências \& Cognição & - & - & Brasil & Interdisciplinar & 1 \\
Distúrbios da Comunicação & - & - & Brasil & Fonoaudiologia & 1 \\
Fisioterapia e Pesquisa & - & - & Brasil & Fisioterapia & 2 \\
Fisioterapia em movimento & - & - & Brasil & Interdisciplinar & 3 \\
J. Hum. Growth Dev & - & - & Brasil & Interdisciplinar & 3 \\
Rev bras ciênc mov & - & - & Brasil & P. em Saúde & 3 \\
Rev Bras Educ Fís Esporte & - & - & Brasil & Ed Física & 1 \\
Revista Brasileira de Futsal & - & - & Brasil & Futebol & 1 \\
e Futebol & - & - & Brasil & Fonoaudiologia & 3 \\
Revista CEFAC & - & - & Espanha & C. do Esporte & 1 \\
Revista de Ciencias Del & - & & & & \\
Deporte & - & Brasil & Educação Esp & 1 \\
Revista de Educação & - & & & \\
Especial & & & & \\
\hline
\end{tabular}

Legenda: Rev Bras Cineantropom Desempenho Hum: Revista Brasileira de Cineantropometria e

Desempenho Humano; Rev int med cienc act fís deporte: Revista Internacional de Medicina y Ciencias de la Actividad Física y el Deporte; Rev bras educ espec: Revista Brasileira de Educação Especial; Cad Bras Ter Ocup $=$ Cadernos Brasileiros de Terapia Ocupacional; J. Hum. Growth Dev = Journal of Human Growth and Development; Rev bras ciênc mov = Revista Brasileira de Ciência e Movimento; Rev Bras Educ Fís Esporte = Revista Brasileira de Educação Física e Esporte; SJR = Scimago Jounal Rank; * = Índice H segundo consulta ao Scimago Jounal Rank; † = Área segundo consulta ao Scimago Jounal Rank. Nos casos em que a revista não apresenta SJR, a área foi consultada no escopo da própria revista; $P$. = Profissões; $C .=$ Ciências; TO = Terapia Ocupacional; Ed Física = Educação Física; Educação Esp = Educação Especial; N = Número de publicações em cada revista.

Fonte: Os autores (2019).

\section{Sobre os estudos}

Os estudos foram realizados prioritariamente nas regiões Sul e Sudeste do Brasil, especialmente nos estados de São Paulo e Santa Catarina. No entanto, podemos observar pesquisas realizadas no Nordeste e fora do Brasil, como apresentado na Figura 3. Dois artigos não informaram o local da pesquisa.

Figura 3 - Distribuição dos locais de realização das pesquisas com a EDM

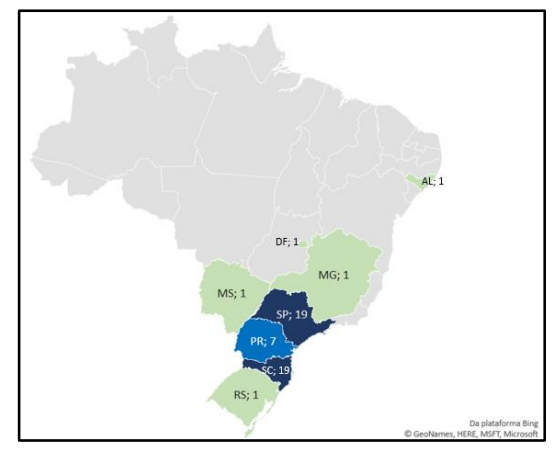

Fonte: Os autores (2019). 
http://dx.doi.org/10.5902/1984686X41510

Podemos observar também que a realização dessas pesquisas possibilitou a conexão e o trabalho conjunto entre 31 universidades e faculdades brasileiras e uma australiana. Essa rede de conexões está representada na Figura 4.

Figura 4 - Rede de conexões entre as Universidades para colaboração na pesquisa e publicação dos artigos. A direção da seta indica a Universidade do primeiro autor e as colaborações estabelecidas

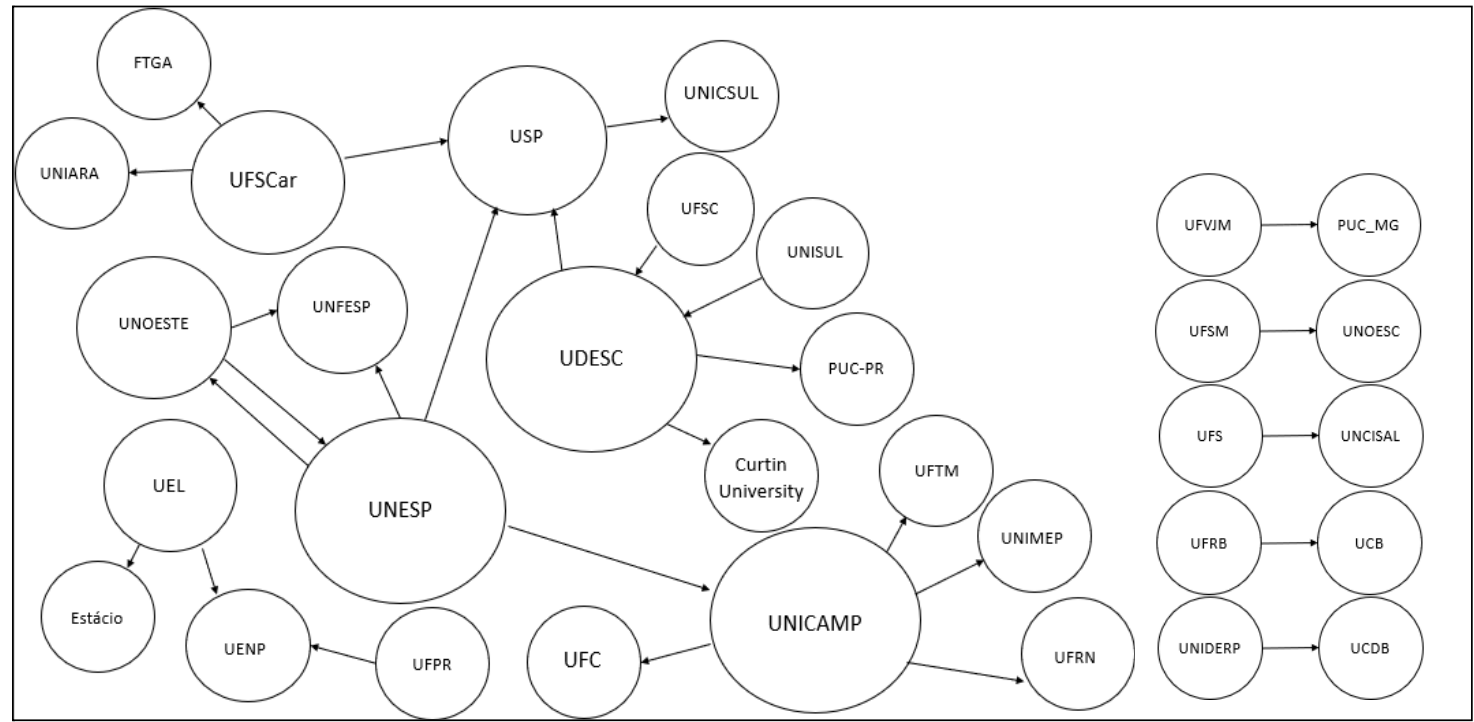

Legenda: UDESC = Universidade do Estado de Santa Catarina; UNESP = Universidade Estadual de Paulista ; UNICAMP = Universidade Estadual de Campinas; USP = Universidade de São Paulo; UFSCar = Universidade Federal de São Carlos; FTGA = Faculdade de Taguatinga; UNIARA = Universidade de Araraquara; UNICSUL = Universidade Cruzeiro do Sul; UFSC =Universidade Federal de Santa Catarina; UNISUL = Universidade do Sul de Santa Catarina; PUC-PR = Pontifícia Universidade Católica do Paraná; UNIFESP = Universidade Federal de São Paulo; UNOESTE = Universidade do Oeste Paulista; UFC = Universidade Federal do Ceará; UFRN = Universidade Federal do Rio Grande do Norte; UNIMEP = Universidade Metodista de Piracicaba; UFTM = Universidade Federal do Triângulo Mineiro; UEL = Universidade Estadual de Londrina; Estácio = Faculdade Estácio de Sá; UENP = Universidade Estadual do Norte do Paraná; UFPR = Universidade Federal do Paraná; UFVJM = Universidade Federal dos Vales do Jequitinhonha e Mucuri; PUC-MG = Pontifícia Universidade Católica de Minas Gerais; UFSM = Universidade Federal de Santa Maria; UNIOESC = Universidade do Oeste de Santa Catarina; UFS = Universidade Federal de Sergipe; UNCISAL = Universidade Estadual de Ciências da Saúde de Alagoas; UFRB = Universidade Federal do Recôncavo da Bahia; UCB = Universidade Católica de Brasília; UNIDERP = Universidade para o Desenvolvimento do Estado e da Região do Pantanal; UCBD = Universidade Católica Dom Bosco.

Fonte: Os autores (2019).

A Tabela 2 apresenta os dados referentes ao tipo de estudo, idioma de publicação, objetivo, população estudada e número de vezes que cada um dos 53 artigos selecionados foi citado. Podemos observar publicações em língua portuguesa, inglesa e em espanhol. Dois tipos de artigo apresentam maior prevalência: a) os de análise de um perfil motor de crianças; b) os de intervenção, onde o desenvolvimento motor é avaliado pré e pós intervenção. Na Tabela 2 também é possível observar que a maior parte dos estudos avalia 
http://dx.doi.org/10.5902/1984686X41510

população de crianças com desenvolvimento atípico, como com transtornos, deficiências ou dificuldades de aprendizagem.

Tabela 2 - Publicações relativas a EDM: referência, idioma, objetivo, população alvo e número de vezes que 0 artigo foi citado

\begin{tabular}{|c|c|c|c|c|}
\hline Referência & Id & Objetivo & População & NC \\
\hline $\begin{array}{c}\text { Caetano } \\
(2005)\end{array}$ & $\mathrm{Pt}$ & $\begin{array}{l}\text { Analisar as mudanças motoras no } \\
\text { intervalo de } 13 \text { meses }\end{array}$ & 35 (3 a 7 anos) & 100 \\
\hline $\begin{array}{l}\text { Rosa Neto } \\
\text { (2010a) }\end{array}$ & $\mathrm{Pt}$ & $\begin{array}{l}\text { Verificar a fidedignidade dos testes de } \\
\text { motricidade fina da EDM }\end{array}$ & 101 (6 a 10 anos) & 79 \\
\hline $\begin{array}{l}\text { Medina- } \\
\text { Papst } \\
(2010)\end{array}$ & $\mathrm{Pt}$ & $\begin{array}{l}\text { Investigar se crianças com dificuldades } \\
\text { de aprendizagem apresentam atraso no } \\
\text { DM }\end{array}$ & $\begin{array}{c}30 \text { crianças com } \\
\text { dificuldades de } \\
\text { aprendizagem (8 a } 10 \\
\text { anos) }\end{array}$ & 73 \\
\hline $\begin{array}{l}\text { Silveira } \\
(2006)\end{array}$ & $\mathrm{Pt}$ & $\begin{array}{l}\text { Analisar a validade de construção dos } \\
\text { testes motores de equilíbrio da EDM }\end{array}$ & 76 (6 a 9 anos) & 51 \\
\hline $\begin{array}{l}\text { Goulardins } \\
\quad(2011)\end{array}$ & In & $\begin{array}{l}\text { Avaliar a QV e o perfil psicomotor de } \\
\text { crianças com TDAH }\end{array}$ & $\begin{array}{l}40 \text { crianças com TDAH } \\
\text { (7 a } 10 \text { anos })\end{array}$ & 38 \\
\hline $\begin{array}{l}\text { Rosa Neto } \\
\text { (2007) }\end{array}$ & Pt & $\begin{array}{l}\text { Avaliar o DM e as características } \\
\text { psicossociais de crianças }\end{array}$ & $\begin{array}{c}31 \text { crianças com } \\
\text { dificuldades de } \\
\text { aprendizagem (6 a } 13 \\
\text { anos) }\end{array}$ & 38 \\
\hline $\begin{array}{l}\text { Rosa } \\
(2008)\end{array}$ & Pt & $\begin{array}{l}\text { Analisar o DM de uma criança com PC } \\
\text { e os efeitos de um programa de } \\
\text { atividades motoras no meio aquático }\end{array}$ & $\begin{array}{l}01 \text { criança com paralisia } \\
\text { cerebral (10 anos) }\end{array}$ & 36 \\
\hline $\begin{array}{l}\text { Fonseca } \\
(2008)\end{array}$ & $\mathrm{Pt}$ & $\begin{array}{l}\text { Verificar a relação entre o nível de DM e } \\
\text { variáveis do contexto de } \\
\text { desenvolvimento }\end{array}$ & 34 crianças ( 6 a 9 anos) & 28 \\
\hline $\begin{array}{l}\text { Okuda } \\
\text { (2011) }\end{array}$ & Pt & $\begin{array}{l}\text { Comparar o desempenho da } \\
\text { coordenação motora fina em escolares }\end{array}$ & $\begin{array}{c}11 \text { escolares com } \\
\text { dislexia e } 11 \text { com TDAH } \\
\text { (6 a } 11 \text { anos })\end{array}$ & 28 \\
\hline $\begin{array}{l}\text { Suzuki } \\
(2005)\end{array}$ & $\mathrm{Pt}$ & $\begin{array}{l}\text { Avaliar se existe alteração do equilíbrio } \\
\text { estático em crianças com diagnóstico } \\
\text { clínico de TDAH }\end{array}$ & $\begin{array}{l}15 \mathrm{com} \text { TDAH e } 15 \mathrm{sem} \\
\text { TDAH (7 a } 11 \text { anos) }\end{array}$ & 28 \\
\hline $\begin{array}{l}\text { Goulardins } \\
\quad(2013)\end{array}$ & In & $\begin{array}{l}\text { Avaliar o perfil motor de crianças com } \\
\text { TDAH }\end{array}$ & $\begin{array}{l}34 \text { crianças com TDAH } \\
\text { e } 32 \text { crianças sem } \\
\text { TDAH ( } 7 \text { a } 11 \text { anos })\end{array}$ & 26 \\
\hline $\begin{array}{l}\text { Mansur } \\
(2006)\end{array}$ & $\mathrm{Pt}$ & $\begin{array}{l}\text { Avaliar o perfil motor de crianças com } \\
\text { deficiência intelectual }\end{array}$ & $\begin{array}{l}20 \text { crianças com DI } \\
\text { moderado ( } 7 \text { a } 15 \text { anos) }\end{array}$ & 22 \\
\hline $\begin{array}{l}\text { Rosa Neto } \\
\text { (2011) }\end{array}$ & Pt & $\begin{array}{l}\text { Verificar o desenvolvimento do } \\
\text { esquema corporal de escolares }\end{array}$ & $\begin{array}{l}39 \text { com dificuldades de } \\
\text { aprendizagem (6 a } 10 \\
\text { anos) }\end{array}$ & 22 \\
\hline $\begin{array}{l}\text { Pavão } \\
\text { (2014) }\end{array}$ & $\begin{array}{l}\text { In } \\
\mathrm{Pt}\end{array}$ & $\begin{array}{l}\text { Verificar o efeito de um protocolo } \\
\text { terapêutico baseado em RV sobre o } \\
\text { desempenho motor e o equilíbrio } \\
\text { funcional }\end{array}$ & $\begin{array}{l}01 \text { criança com Paralisia } \\
\text { Cerebral ( } 7 \text { anos) }\end{array}$ & 21 \\
\hline $\begin{array}{l}\text { Torquato } \\
\text { (2013) }\end{array}$ & $\mathrm{Pt}$ & $\begin{array}{l}\text { Verificar a aquisição de marcos motores } \\
\text { em crianças com SD na equoterapia ou } \\
\text { fisioterapia }\end{array}$ & $\begin{array}{c}33 \text { crianças com } \\
\text { Síndrome de Down (4 e } \\
13 \text { anos) }\end{array}$ & 21 \\
\hline $\begin{array}{l}\text { Poeta } \\
(2011)\end{array}$ & $\mathrm{Pt}$ & Avaliar o DM de crianças obesas & $\begin{array}{l}64 \text { divididas em dois } \\
\text { grupos: eutróficos e } \\
\text { obesos ( } 6 \text { e } 10 \text { anos) }\end{array}$ & 21 \\
\hline
\end{tabular}


Tabela 2 - Publicações relativas a EDM: referência, idioma, objetivo, população alvo e número de vezes que 0 artigo foi citado

\begin{tabular}{|c|c|c|c|c|}
\hline Referência & Id & Objetivo & População & NC \\
\hline $\begin{array}{c}\text { Amaro } \\
(2009)\end{array}$ & $\mathrm{Pt}$ & $\begin{array}{l}\text { Verificar a consistência interna dos } \\
\text { testes de Motricidade Global e Equilíbrio } \\
\text { da EDM }\end{array}$ & $\begin{array}{c}101 \text { crianças (6 a } 10 \\
\text { anos) }\end{array}$ & 19 \\
\hline $\begin{array}{l}\text { Santos } \\
(2013)\end{array}$ & $\mathrm{Pt}$ & $\begin{array}{l}\text { Avaliar o DM participantes de projetos } \\
\text { sociais, esportivos e de não } \\
\text { participantes em atividades estruturadas }\end{array}$ & $\begin{array}{c}136 \text { crianças (8 a } 9 \\
\text { anos) }\end{array}$ & 19 \\
\hline $\begin{array}{l}\text { Fernani } \\
(2013)\end{array}$ & In & $\begin{array}{l}\text { Avaliar o DM de crianças pré e pós- } \\
\text { intervenção motora }\end{array}$ & $\begin{array}{l}28 \text { com dificuldades de } \\
\text { aprendizagem (6 a } 11 \\
\text { anos) }\end{array}$ & 16 \\
\hline $\begin{array}{l}\text { Rosa Neto } \\
\text { (2015) }\end{array}$ & In & $\begin{array}{l}\text { Comparar o DM de crianças com TDAH } \\
\text { com crianças com desenvolvimento } \\
\text { típico }\end{array}$ & $\begin{array}{l}50 \text { com TDAH e } 150 \\
\text { com desenvolvimento } \\
\text { típico ( } 5 \text { a } 10 \text { anos) }\end{array}$ & 15 \\
\hline $\begin{array}{l}\text { Poeta } \\
(2007)\end{array}$ & Es & Avaliar o DM de crianças com TDAH & $\begin{array}{l}31 \text { com indicativos de } \\
\text { TDAH ( } 7 \text { a } 10 \text { anos) }\end{array}$ & 14 \\
\hline $\begin{array}{l}\text { Prestes } \\
(2010)\end{array}$ & $\mathrm{Pt}$ & $\begin{array}{l}\text { Investigar os benefícios da equoterapia } \\
\text { no DM e autopercepção de escolares }\end{array}$ & $\begin{array}{l}02 \text { com dificuldade de } \\
\text { aprendizagem (10 e } 11 \\
\text { anos) }\end{array}$ & 13 \\
\hline $\begin{array}{l}\text { Rosa Neto } \\
(2010 \mathrm{~b})\end{array}$ & Pt & $\begin{array}{l}\text { Investigar o perfil motor de escolares e } \\
\text { analisar a confiabilidade da EDM }\end{array}$ & $\begin{array}{c}101 \text { escolares (6 a } 10 \\
\text { anos) }\end{array}$ & 13 \\
\hline $\begin{array}{l}\text { Rosa Neto } \\
\text { (2013) }\end{array}$ & $\begin{array}{l}\text { In } \\
\mathrm{Pt}\end{array}$ & $\begin{array}{l}\text { Analisar a leitura e escrita em escolares } \\
\text { com lateralidade cruzada }\end{array}$ & $\begin{array}{l}166 \text { escolares (8 e } 9 \\
\text { anos) }\end{array}$ & 12 \\
\hline $\begin{array}{l}\text { Alano } \\
(2011)\end{array}$ & $\mathrm{Pt}$ & $\begin{array}{l}\text { Avaliar o DM e o nível de aptidão física } \\
\text { de escolares }\end{array}$ & $\begin{array}{l}52 \text { com dificuldades na } \\
\text { aprendizagem (7 a } 11 \\
\text { anos) }\end{array}$ & 11 \\
\hline $\begin{array}{l}\text { Crippa } \\
(2003)\end{array}$ & $\mathrm{Pt}$ & $\begin{array}{l}\text { Verificar o perfil motor de crianças que } \\
\text { praticam atividades recreativas }\end{array}$ & 19 crianças (4 e 5 anos) & 11 \\
\hline $\begin{array}{l}\text { Santos } \\
\text { APM } \\
(2015)\end{array}$ & Pt & $\begin{array}{l}\text { Avaliar o DM de uma criança com } \\
\text { Síndrome de Williams e verificar os } \\
\text { efeitos de um programa de intervenção } \\
\text { motora }\end{array}$ & $\begin{array}{c}01 \text { criança com } \\
\text { Síndrome de Williams ( } 9 \\
\text { anos) }\end{array}$ & 11 \\
\hline $\begin{array}{l}\text { Camargos } \\
\quad(2011)\end{array}$ & $\mathrm{Pt}$ & $\begin{array}{l}\text { Comparar o DM de crianças nascidas } \\
\text { pré-termo e a termo }\end{array}$ & $\begin{array}{l}13 \text { crianças ( } 7 \text { e } 8 \text { anos) } \\
\text { em cada grupo }\end{array}$ & 10 \\
\hline $\begin{array}{l}\text { Rocha } \\
(2010)\end{array}$ & $\mathrm{Pt}$ & $\begin{array}{l}\text { Investigar as contribuições da iniciação } \\
\text { esportiva para o DM }\end{array}$ & 80 crianças (6 a 9 anos) & 10 \\
\hline $\begin{array}{l}\text { Cardeal } \\
(2013)\end{array}$ & $\mathrm{Pt}$ & $\begin{array}{l}\text { Verificar o efeito da estimulação motora, } \\
\text { nas respostas da função cognitiva de } \\
\text { crianças }\end{array}$ & $\begin{array}{c}80 \text { crianças ( } 6 \text { a } 10 \\
\text { anos) }\end{array}$ & 10 \\
\hline $\begin{array}{l}\text { Rondon } \\
\text { (2010) }\end{array}$ & Pt & $\begin{array}{l}\text { Avaliar as contribuições de um } \\
\text { programa de atividades rítmicas para o } \\
\text { desenvolvimento motor de escolares }\end{array}$ & 16 escolares (8 anos) & 9 \\
\hline $\begin{array}{c}\text { Barbosa } \\
(2014)\end{array}$ & Pt & $\begin{array}{l}\text { Verificar o efeito da equoterapia sobre o } \\
\text { desenvolvimento psicomotor de } \\
\text { crianças com TDAH }\end{array}$ & $\begin{array}{c}05 \text { crianças com } \\
\text { indicativos de TDAH ( } 7 \\
\text { a } 10 \text { anos) }\end{array}$ & 7 \\
\hline $\begin{array}{l}\text { Lorenzo } \\
\text { (2015) }\end{array}$ & $\mathrm{Pt}$ & $\begin{array}{l}\text { Avaliar os resultados de intervenções } \\
\text { com uso da RV sobre parâmetros } \\
\text { psicomotores de uma criança }\end{array}$ & $\begin{array}{l}01 \text { com Síndrome de } \\
\text { Down (10 anos) }\end{array}$ & 7 \\
\hline $\begin{array}{c}\text { Campos } \\
(2017)\end{array}$ & $\begin{array}{l}\text { In } \\
\mathrm{Pt}\end{array}$ & $\begin{array}{l}\text { Avaliar um programa de intervenção } \\
\text { para criança com atraso no DM }\end{array}$ & 01 criança (4 anos) & 5 \\
\hline
\end{tabular}


Tabela 2 - Publicações relativas a EDM: referência, idioma, objetivo, população alvo e número de vezes que o artigo foi citado

\begin{tabular}{|c|c|c|c|c|}
\hline Referência & Id & Objetivo & População & NC \\
\hline $\begin{array}{l}\text { Soares } \\
(2015)\end{array}$ & $\begin{array}{l}\text { In } \\
\mathrm{Pt}\end{array}$ & $\begin{array}{l}\text { Avaliar e comparar o DM de crianças } \\
\text { com e sem queixas de dificuldade de } \\
\text { aprendizagem }\end{array}$ & $\begin{array}{l}22 \text { com e sem de } \\
\text { dificuldade de } \\
\text { aprendizagem (7 a } 14 \\
\text { anos) }\end{array}$ & 4 \\
\hline $\begin{array}{l}\text { Silva } \\
(2016)\end{array}$ & $\ln$ & $\begin{array}{l}\text { Comparar o DM de crianças nascidas } \\
\text { prematuras estimuladas precocemente } \\
\text { e crianças nascidas a termo, na fase } \\
\text { motora fundamental }\end{array}$ & $\begin{array}{c}20 \text { crianças; } 10 \\
\text { nascidas prematuras e } \\
10 \text { nascidas a termo ( } 3 \\
\text { anos) }\end{array}$ & 4 \\
\hline $\begin{array}{l}\text { Santos LB } \\
(2015 a)\end{array}$ & $\begin{array}{l}\text { Es } \\
\text { In }\end{array}$ & $\begin{array}{l}\text { Analisar o perfil das características } \\
\text { motoras de crianças }\end{array}$ & $\begin{array}{l}284 \text { eutróficas, com } \\
\text { sobrepeso e obesas ( } 6 \\
\text { a } 10 \text { anos) }\end{array}$ & 3 \\
\hline $\begin{array}{l}\text { Santos CR } \\
\quad(2015)\end{array}$ & $\mathrm{Pt}$ & $\begin{array}{l}\text { Verificar o impacto do ballet clássico e } \\
\text { do futsal sobre indicadores de } \\
\text { motricidade global e de equilíbrio em } \\
\text { crianças }\end{array}$ & $\begin{array}{c}160 \text { crianças, pré- } \\
\text { púberes, eutróficas ( } 7 \text { a } \\
10 \text { anos) }\end{array}$ & 2 \\
\hline $\begin{array}{l}\text { Santos LB } \\
(2015 b)\end{array}$ & Es & $\begin{array}{l}\text { Descrever e comparar o DM de } \\
\text { escolares que praticam atividades } \\
\text { esportivas extraescolares }\end{array}$ & $\begin{array}{l}117 \text { escolares } \\
\text { espanhóis ( } 6 \text { a } 10 \text { anos) }\end{array}$ & 2 \\
\hline $\begin{array}{l}\text { Silva AZ } \\
(2017)\end{array}$ & $\ln$ & $\begin{array}{l}\text { Avaliar os efeitos de um programa de } \\
\text { intervenção no DM de escolares }\end{array}$ & $\begin{array}{l}91 \text { escolares (8 a } 10 \\
\text { anos) }\end{array}$ & 2 \\
\hline $\begin{array}{l}\text { Anjos } \\
(2018)\end{array}$ & $\begin{array}{l}\text { In } \\
\mathrm{Pt}\end{array}$ & $\begin{array}{l}\text { Comparar o DM de crianças praticantes } \\
\text { e não praticantes de dança educativa }\end{array}$ & $\begin{array}{l}85 \text { do } 1^{\circ} \text { ano do ensino } \\
\text { fundamental }\end{array}$ & 1 \\
\hline $\begin{array}{l}\text { Cruz } \\
(2017)\end{array}$ & $\mathrm{Pt}$ & $\begin{array}{l}\text { Analisar a relação entre DM e nível de } \\
\text { atividade física com o IMC de escolares } \\
\text { com excesso de peso }\end{array}$ & $\begin{array}{c}50 \text { crianças com } \\
\text { sobrepeso e obesas e } \\
35 \text { crianças eutróficas }\end{array}$ & 1 \\
\hline $\begin{array}{l}\text { Iwabe } \\
(2010)\end{array}$ & $\mathrm{Pt}$ & $\begin{array}{l}\text { Relatar os aspectos funcionais de uma } \\
\text { criança com mucopolissacaridose tipo } 1\end{array}$ & 01 (34 meses) & 1 \\
\hline $\begin{array}{l}\text { Matsunaga } \\
\quad(2016)\end{array}$ & $\mathrm{Pt}$ & $\begin{array}{l}\text { Avaliar o efeito de atividades } \\
\text { psicomotoras no DM de crianças }\end{array}$ & 16 crianças (5 anos) & 1 \\
\hline $\begin{array}{l}\text { Santos } \\
(2016)\end{array}$ & $\begin{array}{l}\text { In } \\
\mathrm{Pt}\end{array}$ & $\begin{array}{l}\text { Analisar o perfil biopsicossocial de } \\
\text { escolares com atraso no DM }\end{array}$ & $\begin{array}{l}17 \text { escolares com atraso } \\
\text { no DM (8 e } 9 \text { anos) }\end{array}$ & 1 \\
\hline $\begin{array}{l}\text { Trindade } \\
(2016)\end{array}$ & $\mathrm{Pt}$ & $\begin{array}{l}\text { Avaliar a idade motora em crianças com } \\
\text { SD }\end{array}$ & $\begin{array}{l}07 \text { crianças com } \\
\text { Síndrome de Down }\end{array}$ & 1 \\
\hline $\begin{array}{l}\text { Arnoni } \\
(2018)\end{array}$ & $\begin{array}{l}\text { In } \\
\mathrm{Pt}\end{array}$ & $\begin{array}{l}\text { Verificar o efeito de uma intervenção em } \\
\text { RV no autoconceito, equilíbrio, } \\
\text { desempenho motor e sucesso } \\
\text { adaptativo de crianças com PC }\end{array}$ & $\begin{array}{c}08 \text { crianças com } \\
\text { Paralisia Cerebral ( } 5 \text { a } \\
14 \text { anos })\end{array}$ & 0 \\
\hline $\begin{array}{l}\text { Del } \\
\text { Agostini } \\
\text { (2015) }\end{array}$ & $\mathrm{Pt}$ & $\begin{array}{l}\text { Demonstrar a importância dos jogos } \\
\text { pré-desportivos para o desenvolvimento } \\
\text { da motricidade global de crianças }\end{array}$ & 08 crianças (6 e 7 anos) & 0 \\
\hline $\begin{array}{l}\text { Laux } \\
(2016)\end{array}$ & $\begin{array}{l}\text { In } \\
\mathrm{Pt}\end{array}$ & $\begin{array}{l}\text { Identificar a quantidade de sujeitos } \\
\text { disgráficos em uma população } \\
\text { específica e verificar o efeito de uma } \\
\text { intervenção psicomotora }\end{array}$ & $\begin{array}{l}35 \text { crianças disgráficas } \\
\text { (9 e } 10 \text { anos })\end{array}$ & 0 \\
\hline $\begin{array}{l}\text { Maronesi } \\
(2015)\end{array}$ & $\mathrm{Pt}$ & $\begin{array}{l}\text { Verificar o efeito da intervenção na } \\
\text { motricidade global, fina e equilíbrio }\end{array}$ & $\begin{array}{l}01 \text { criança com atraso } \\
\text { no DM (4 anos) }\end{array}$ & 0 \\
\hline
\end{tabular}


Tabela 2 - Publicações relativas a EDM: referência, idioma, objetivo, população alvo e número de vezes que o artigo foi citado

\begin{tabular}{cclcc}
\hline Referência & Id & Objetivo & População & NC \\
\hline $\begin{array}{c}\text { Okuda } \\
\text { (2010) }\end{array}$ & Pt & Caracterizar o perfil motor de escolares & $\begin{array}{c}\text { 6 escolares com TEA (5 } \\
\text { a 10 anos) }\end{array}$ & 0 \\
$\begin{array}{c}\text { Santos } \\
\text { (2010) }\end{array}$ & Pt & $\begin{array}{l}\text { Analisar o DM de uma criança com } \\
\text { Síndrome de Down e verificar os efeitos } \\
\text { de um programa de intervenção motora }\end{array}$ & $\begin{array}{c}\text { síndrome de Down }(7 \\
\text { anos) }\end{array}$ & 0 \\
$\begin{array}{c}\text { Silva } \\
(\mathbf{2 0 1 4})\end{array}$ & Pt & $\begin{array}{l}\text { Traçar o perfil do desenvolvimento } \\
\text { motor de crianças com baixo } \\
\text { rendimento escolar }\end{array}$ & 43 (9 a 11 anos) & 0 \\
& & & \\
\hline
\end{tabular}

Legenda: Id. - Idioma, In - Inglês, Pt - Português, Es - Espanhol; NC - número de citações; EDM - Escala de Desenvolvimento Motor; DM - Desenvolvimento Motor; QV - Qualidade de vida; TDAH - Transtorno de déficit de atenção e hiperatividade; DI - Deficiência intelectual; RV - Realidade virtual; PC - Paralisia cerebral; TEA - Transtorno do Espectro Autista.

Fonte: Os autores (2019).

Dentre os estudos analisados, foram encontradas 94 diferentes palavras-chave que, quando observadas individualmente, podem indicar temas importantes relacionados com a Escala de Desenvolvimento Motor. Conforme representado no Figura 5, observa-se que o descritor "Desenvolvimento Infantil" foi o mais utilizado (14 vezes). Outras palavras relacionadas diretamente ao desenvolvimento motor também aparecem entre as mais citadas: Desenvolvimento Motor, Destreza Motora, Desempenho Psicomotor. Além disso, pode-se perceber que termos relacionados a grupos específicos de crianças, como TDAH, Síndrome de Down e Paralisia Cerebral, também foram comuns dentre as palavras-chave encontradas nesta pesquisa. Os quadros 1 e 2 apresentam as palavras-chave que aparecem apenas uma ou duas vezes.

Figura 5 - Número de vezes que cada palavra chave aparece nos artigos

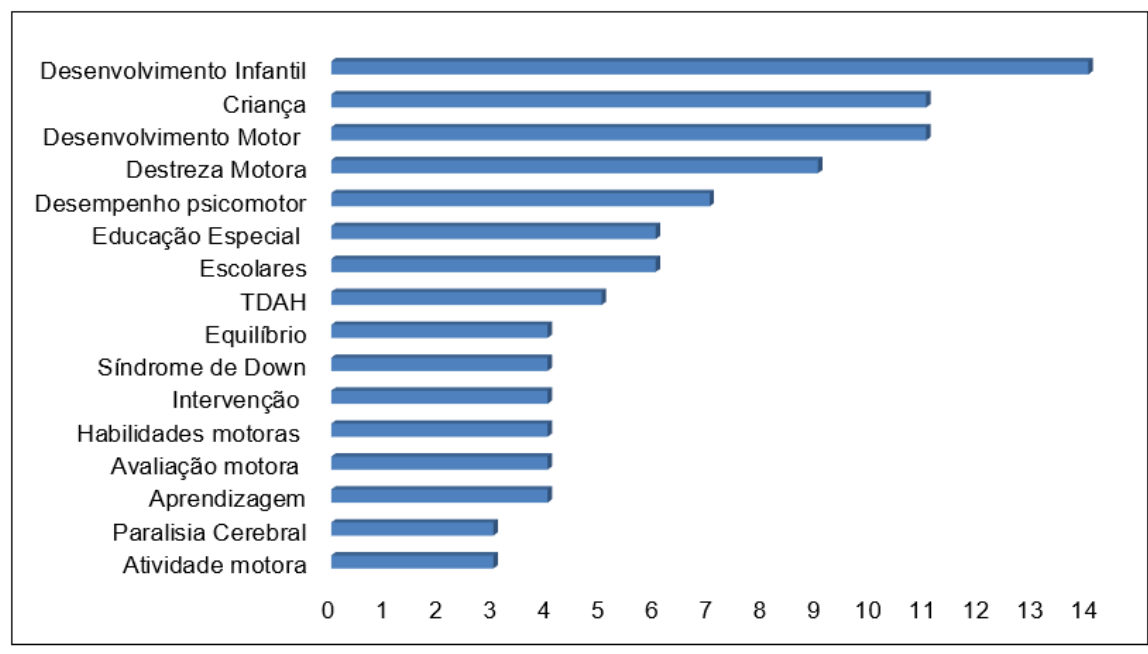

Legenda: TDAH: Transtorno de Déficit de Atenção e Hiperatividade. Fonte: Os autores (2019). 
http://dx.doi.org/10.5902/1984686X41510

Quadro 1 - Palavras que aparecem duas vezes nas palavras-chave

Aptidão Física; Dificuldade de aprendizagem; Realidade Virtual; Equoterapia; Educação Física e Treinamento; Obesidade; Movimento; Terapia Ocupacional; Pré-escolares; Motricidade global; Perfil motor; Fisioterapia; Avaliação; Reabilitação; Baixo Rendimento Escolar; Esquema corporal; Consistência interna; Coeficiente alpha.

Fonte: Os autores (2019).

Quadro 2 - Palavras que aparecem uma vez nas palavras-chave

Estudos de Validação; Saúde escolar; Dança; Sobrepeso; Grupos etários;
Prematuro; Brincadeira; Atividades recreativas; Obesidade infantil;
Coordenação motora; Jogos coletivos; Crianças de 6 e 7 anos; Contexto de
desenvolvimento; Qualidade de vida; Deficiências do desenvolvimento;
Mucopolissacaridose I; Transtornos de Aprendizagem; Adolescentes;
Deficiência mental moderada; Coordenação Motora Fina; Coordenação
Motora Global; Transtorno da Coordenação Motora; Transtorno Autístico;
Dislexia; Transtorno da Falta de Atenção com Hiperatividade; Equilíbrio
postural; Terapia de exposição à realidade virtual; Alterações motoras;
Desempenho motor; Autopercepção; Esporte; Impacto Psicossocial;
Distúrbios da aprendizagem; Psiquiatria infantil; Relação interdisciplinar;
Neurologia comportamental; Escala de desenvolvimento motor; Motricidade
fina; Leitura; Escrita Manual; Lateralidade Funcional; Estudantes; Condições
sociais; Síndrome de Williams; Projeto social; Prática esportiva; Atividade
esportiva; Iniciação Esportiva; Nascimento a Termo; Nascimento Prematuro;
Validade dos testes; Psicomotor; Transtorno de Déficit de Atenção;
Hiperatividade; Controle postural; Movimento Humano; Educação Física;
Função Executiva; Atividade Rítmica; Escola.

Fonte: Os autores (2019).

Com intuito de verificar a qualidade e confiabilidade dos termos utilizados como palavras-chave nos estudos analisados nesta revisão, os 94 descritores registrados foram consultados no vocabulário estruturado Descritores em Ciências da Saúde (DeCS, 2018), que servem como uma linguagem única na indexação de artigos de revistas científicas, dentre outros materiais. Sabe-se ser de extrema importância a utilização de termos incluídos no DeCS, visto que ampliam, em grandes proporções, a visibilidade dos estudos no resgate da produção científica mediante buscas em bases de dados.

A busca na plataforma DeCS foi realizada consultando-se: Descritor Exato, em Português, por Índice Alfabético. Dentre as 94 palavras-chave consultadas, apenas 42 aparecem como termos primários na hierarquia deste vocabulário (Tabela 3). Além destes, outros 10 termos surgem como sinônimos de descritores primários. Ao analisar os 16 
http://dx.doi.org/10.5902/1984686X41510

termos-descritores que foram usados como palavras-chaves mais recorrentes nos artigos analisados (Figura 5), 11 estão contemplados no DeCS, sendo que 9 são descritores primários e 2 surgem como sinônimos de outro descritor.

Tabela 3 - Descritores primários na plataforma DeCS

(continua)

\section{Descritor português \\ Desenvolvimento Infantil \\ Criança \\ Destreza Motora \\ Desempenho Psicomotor}

\section{Educação Especial Síndrome de Down Aprendizagem Paralisia Cerebral}

\section{Atividade Motora Aptidão Física Realidade Virtual}

Educação Física e
Treinamento
Obesidade
Movimento
Terapia Ocupacional
Fisioterapia
Reabilitação
Baixo Rendimento Escolar
Estudos de Validação
Dança

\section{Sobrepeso} Grupos Etários

\section{Qualidade de Vida Deficiências do Desenvolvimento}

\section{Mucopolissacaridose I}

\section{Transtornos de Aprendizagem Transtorno Autístico Dislexia}

\section{Sinônimos - português}

D. dos Lactentes; D. das Crianças; D; das Crianças em Idade PréEscolar; D. dos Pré-Escolares; D. do Lactente; D. de Pré-escolares; D. da Criança em Idade Pré-Escolar; D. da Criança Pré-Escolar; D. do PréEscolar; D. da Criança; D. Pré-Escolar

Crianças

Habilidades Motoras; Habilidade Motora

Desempenho Perceptual-Motor; Coordenação Visiomotora;

Desempenho Sensório-Motor

Mongolismo; Trissomia do 21; Trissomia do Cromossomo 21

Aprendizado; Fenomenografia

Doença de Little; Diplegia Espástica; Paralisia Cerebral Diplégica

Infantil;

Paralisia Cerebral Monoplégica; Paralisia Cerebral Quadriplégica Infantil

Forma Física; Habilidade Física

Realidade Virtual Educativa; Realidade Virtual Instrucional; Realidades

Virtuais Educativas; Realidades Virtuais Instrucionais.

Educação Física; Educação e Treinamento Físico

Tratamento da Obesidade

Curso de Terapia Ocupacional

Especialidade Fisioterapia; Curso de Fisioterapia

Habilitação

Balé; Ballet; Dança em Linha; Dança Hip Hop; Dança Jazz; Dança

Salsa; Dança Moderna; Danças; Hip Hop (Dança); Jazz (Dança); Salsa (Dança); Square Dance; Dança de Quadrilha; Sapateado

Faixa de Idade; Faixa Etária; Faixas de Idade; Faixas Etárias; Grupo Etário; Grupo de Idade; Grupos por Idade

Qualidade de Vida Relacionada à Saúde; HRQOL; QVRS

Desvios do Desenvolvimento Infantil; Transtornos do Desenvolvimento Infantil; Transtornos Específicos do Desenvolvimento Infantil;

Transtornos de Atraso do Desenvolvimento

Síndrome de Hurler; Síndrome de Pfaundler-Hurler; Lipocondrodistrofia;

Síndrome de Hurler-Scheie; Mucopolissacaridose V; Síndrome de

Scheie

Deficiências do Aprendizado; Transtornos de Aprendizado; Transtorno do Desenvolvimento Acadêmico; Deficiências da Aprendizagem

Autismo; Autismo Infantil; Síndrome de Kanner

Dificuldade de Desenvolvimento de Leitura; Dislexia de

Desenvolvimento; Transtorno da Leitura; Alexia; Transtorno do

Desenvolvimento da Leitura 
http://dx.doi.org/10.5902/1984686X41510

Tabela 3 - Descritores primários na plataforma DeCS

(conclusão)

Descritor português

Transtorno do Déficit de

Atenção com Hiperatividade

Equilíbrio Postural

Terapia de Exposição à

Realidade Virtual

Impacto Psicossocial

Psiquiatria Infantil

Leitura

Escrita Manual

Lateralidade Funcional

\section{Estudantes}

Condições Sociais

Síndrome de Williams

Nascimento a Termo

Nascimento Prematuro

Função Executiva

\section{Sinônimos - português}

Disfunção Encefálica Mínima; Síndrome Hipercinética; Disfunção

Cerebral Mínima; Transtorno de Hiperatividade e Falta de Atenção;

Transtorno de Hiperatividade e Déficit de Atenção; Transtorno do Déficit de Atenção; Transtorno da Falta de Atenção; Transtorno da Falta de Atenção com Hiperatividade; TDAH; ADHD

Terapia com Exposição à Realidade Virtual

Pedopsiquiatria; Psiquiatria da Infância

Ambidestrismo; Lateralidade Comportamental; Lateralidade;

Lateralidade de Controle Motor; Escrita em Espelho; Modalidades de Lados do Corpo; Sintomas Cruzados

Aluno; Alunos; Estudante

Condição Social; Condições de Vida

Síndrome de Fácies de Elfo; Síndrome do Gene Contíguo de Williams

Parto a Termo

Controle Executivo

Fonte: Os autores (2019).

\section{Sobre a autoria}

A escala foi desenvolvida e publicada no ano de 2002 por Francisco Rosa Neto e esse aparece como autor em 23\% dos artigos pesquisados, como observado na Figura 6. Desses, o autor aparece em 10\% como primeiro autor e em $11 \%$ como orientador ou coordenador da pesquisa.

Figura 6 - Aparições como autor de Francisco Rosa Neto

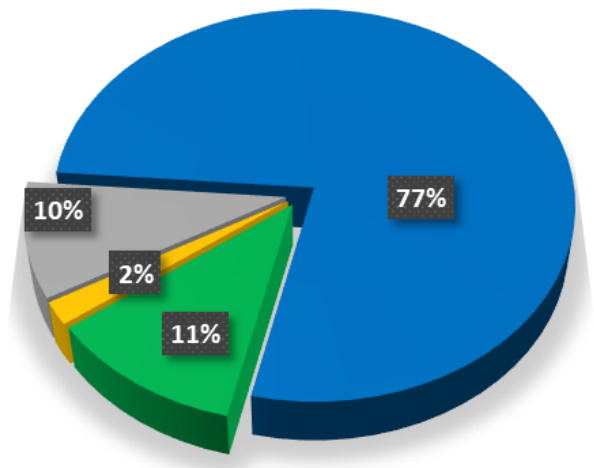

- $1^{\circ}$ autor $\quad 2^{\circ}$ autor Último autor $\quad$ Não aparece na autoria

Fonte: Os autores (2019). 
http://dx.doi.org/10.5902/1984686X41510

Ressalta-se que 77\% das pesquisas acontecerem sem a participação ou relação com Francisco Rosa Neto, autor da EDM. Entretanto, esse é o autor que mais vezes publicou estudos com a utilização da EDM (6 artigos), tendo como principais colaboradoras, mestrandos e doutorandos do Laboratório de Desenvolvimento Humano (LADEHU) da Universidade do Estado de Santa Catarina (UDESC).

\section{Discussão}

Considerando a importância da avaliação do desenvolvimento motor para identificação precoce de atrasos no desenvolvimento e a ampla aplicação da Escala de Desenvolvimento Motor como um instrumento viável de identificação e monitoramento desses riscos, o objetivo deste estudo foi analisar a produção científica relacionada à EDM (ROSA NETO, 2015) por meio de uma análise bibliométrica, analisando os dados referentes a publicações, estudos e autorias.

\section{Sobre as publicações}

A primeira publicação ocorreu em 2003 (CRIPPA, et al., 2003) (Figura 2), com um estudo de avaliação motora de pré-escolares que praticam atividades recreativas. Um aumento nas publicações foi observado a partir do ano 2010 , com $79,63 \%$ das publicações entre os anos 2010 e 2017.

Foi possível observar que a maioria dos artigos estão publicados em revista de medicina e das profissões em saúde (segundo consulta ao SJR - Tabela 1). Apesar dessa constatação, outros periódicos com especificidade nas áreas da saúde (como da psicologia, fisioterapia, terapia ocupacional, fonoaudiologia) e educação (educação especial), também têm publicado artigos com a utilização da EDM, o que corrobora a afirmação do autor da escala, de que esse instrumento pode ser utilizado por profissionais de diferentes áreas, englobando a saúde, a educação e áreas afins (ROSA NETO, 2015).

Dentre as publicações, a Revista Brasileira de Educação Especial e a Revista Brasileira de Cineantropometria e Desempenho Humano foram as que mais publicaram artigos utilizando a EDM como instrumento de avaliação, com sete e cinco publicações respectivamente. A EDM é utilizada principalmente com crianças com desenvolvimento atípico, tentando identificar áreas motoras com maiores dificuldades, o que pode ter contribuído para esse número de publicações na Revista Brasileira de Educação Especial, responsável por cerca de $13 \%$ do total dos 54 artigos encontrados. Dentre as revistas 
http://dx.doi.org/10.5902/1984686X41510

incluídas nesta pesquisa, a Research in Developmental Disabilities e a Revista Brasileira de Psiquiatria apresentam o maior índice SJR, sendo $(0,90)$ e $(0,80)$ respectivamente. $O$ portal SJR permite a publicação seletiva de relatórios dinâmicos com indicadores baseados nas citações entre os trabalhos científicos indexados no Scopus, que possibilitam classificar o desempenho e impacto de revistas científicas e de países. Entre os indicadores para medir o impacto, encontra-se o novo SJR e o H Index (SCIMAGO [s.d.]).

Esses dados apontam para a direção da avaliação de crianças com atrasos e transtornos no sentido de compreensão tanto das variáveis da saúde quanto da educação. A avaliação de atrasos e dificuldades motoras podem indicar relações significativas de desenvolvimento motor e cognitivo, ressaltados pelos paralelos existentes entre o desenvolvimento motor e o desenvolvimento cognitivo, destacando-se a estreita relação entre o que a criança é capaz de aprender com o que é capaz de realizar (ROSA NETO et al., 2010).

É na infância, particularmente no início do processo de escolarização, que ocorre um amplo incremento das habilidades motoras, e essas habilidades constituem componentes de domínio básico tanto para a aprendizagem motora quanto para as atividades de formação escolar (MEDINA; ROSA; MARQUES, 2006). Identificar e monitorar alterações e atrasos no desenvolvimento possibilita obter esclarecimentos sobre estratégias instrutivas e intervencionistas o que permite a profissionais da saúde e da educação a programação de intervenções condizentes, assegurando o caminho concreto entre a condição inicial apresentada pelo indivíduo e os objetivos propostos (SILVEIRA et al., 2006; VIEIRA; RIBEIRO; FORMIGA, 2009).

\section{Sobre os estudos}

As publicações acabam se destacando nas regiões sul e sudeste do Brasil (Figura 3), o que coincide com as regiões onde se concentram os cursos de pós-graduação com os maiores conceitos pela CAPES (2017). Dos 53 estudos, 38 foram realizados nos estados de Santa Catarina e São Paulo. Esse fato concorda e fica visível com as colaborações estabelecidas entre as Universidades apresentado na Figura 4, com destaque para a rede de conexões formada por pesquisadores participantes da UDESC, localizada na região sul do Brasil e instituição de origem do autor da Escala. A UNESP aparece com uma grande conexão, entretanto, ressalta-se que neste estudo foram unidas a UNESP de Rio Claro, Presidente Prudente, Marília e Botucatu, o que pode ter facilitado para a maior conexão 
http://dx.doi.org/10.5902/1984686X41510

desta instituição (Figura 4). Destaca-se a importância da conexão entre os pesquisadores de diferentes instituições, o que contribui para a ampliação da rede de conhecimentos e divulgação dos mesmos.

Dentre os temas abordados, os estudos avaliaram crianças com e sem dificuldade no rendimento escolar, com deficiência intelectual, com TDAH, crianças obesas e praticantes de alguma modalidade esportiva, além de estudos de acompanhamento/intervenção. Dos artigos encontrados, o primeiro que relatou a utilização da escala (CRIPPA et al., 2003) foi o único que avaliou crianças com desenvolvimento típico em idade pré-escolar, mostrando que essa é uma área que pode ser bastante explorada ainda. Vale destacar que a maior parte dos estudos foi realizada com crianças em idade escolar (Ensino Fundamental) e a EDM permite avaliar crianças a partir dos dois anos de idade (ROSA NETO, 2015).

O interesse em pesquisas sobre o tema justifica-se com base na literatura internacional, a qual aponta que de $5 \%$ a $6 \%$ das crianças em idade escolar apresentam diagnóstico clínico de transtorno motor (APA, 2013). Em complemento, pesquisas recentes no contexto brasileiro mostram que essa prevalência pode ser maior. Silva AP (2017), ao avaliar 265 crianças de 3 a 5 anos, encontrou déficits motores em 14,3\% dos indivíduos avaliados. Maggi e colaboradores (2014) encontraram um percentual de $19 \%$ de crianças com atrasos do desenvolvimento motor. Ainda, Valentini e colaboradores (2012), a partir da avaliação de 152 crianças dos três estados na Região Sul, encontraram uma prevalência de $35 \%$ de crianças de 4 a 6 anos com indicações de transtorno motor. Essas desordens ou atrasos motores podem interferir na maturidade global da criança, afetando o desenvolvimento de suas relações sociais, execução nas tarefas de vida diária, aspectos cognitivos, aprendizagem e linguagem (LAMÔNICA; PICOLINI, 2009).

Vale destacar que a maioria dos estudos foram realizados em crianças com desenvolvimento atípico. As crianças com transtornos do desenvolvimento, síndromes ou dificuldades de aprendizagem foram as mais avaliadas, como descrito nos objetivos dos estudos apresentados na tabela 2. Essa avaliação é compreensível tendo em vista que a Escala pode apontar as áreas com maior dificuldade apresentada pela criança e com isso direcionar intervenções e auxiliar diagnósticos. Essa preocupação com crianças com transtornos e dificuldades de aprendizagem também fica visível nas palavras-chave apresentadas. O descritor "Desenvolvimento infantil" foi o mais utilizado nas pesquisas analisadas, seguido por descritores específicos, que caracterizam a população estudada, 
http://dx.doi.org/10.5902/1984686X41510

como nos casos de "TDAH", "obesidade", "Síndrome de Down”, "paralisia cerebral" e "dificuldade de aprendizagem", por exemplo.

\section{Sobre a autoria}

O autor da escala, Francisco Rosa Neto, aparece como primeiro ou último autor em $21 \%$ dos artigos analisados e totaliza $23 \%$ de autoria dos artigos selecionados para este estudo. Este dado era esperado, já que na instituição de origem do autor, há curso de pósgraduação em nível de mestrado e doutorado, viabilizando pesquisas utilizando a EDM como o instrumento principal do estudo. Por outro lado, ressalta-se que nos $77 \%$ restantes, o autor da escala não fez parte da autoria dos estudos, o que sugere um desprendimento do idealizador da mesma e uma larga utilização da EDM nas Universidades, especialmente as brasileiras. Ainda sobre a autoria, os artigos mostram que a escala tem sido utilizada por profissionais e pesquisadores de diversas áreas, como a psicologia, fisioterapia, psiquiatria, entre outras, o que sugere que esses profissionais têm agregado a EDM em sua prática profissional e de pesquisa, ampliando a gama de utilização e a população estudada com a mesma.

Cabe ressaltar que o distanciamento entre as publicações com a EDM e seu autor propositor parece dar identidade própria a escala e assim, favorecer a exploração de diversas possibilidades de associação da avaliação motora com outras escalas (GOULARDINS, 2011), a outras áreas do desenvolvimento infantil (CAMARGOS et al., 2011; CARDEAL et al., 2013), a contextos específicos (FONSECA; BELTRAME; TKAC, 2008), entre outros que podem significar resultados científicos em diferentes áreas de conhecimento.

\section{Limitações}

Como limitações, a pesquisa apresentou foco nas publicações, estudos e autores, deixando para próximos estudos aprofundamentos sobre a qualidade e objetivos específicos das pesquisas. Outro ponto relevante, podemos observar que a maioria dos estudos incluídos foi conduzido nas regiões Sul e Sudeste, deixando uma hipótese a ser aprofundada da relação com a distribuição de recursos para ensino e pesquisa e a qualidade dos programas de pós-graduação. 
http://dx.doi.org/10.5902/1984686X41510

\section{Conclusões}

A partir da abordagem bibliométrica no esforço de analisar a literatura especializada sobre a utilização da EDM na avaliação do desenvolvimento motor de crianças, foi possível constatar um aumento da abrangência quanto a utilização da escala em pesquisas e um aumento em números absolutos de publicações a partir de 2010. Esses dados se mostram condizentes com o aumento no número de publicações em revistas nacionais e internacionais e com maior relevância científica para as áreas da saúde e da educação.

As publicações de maior impacto nos periódicos da área da saúde revelam uma aceitação da EDM como ferramenta de avaliação do desenvolvimento motor infantil, especialmente em crianças com transtornos do desenvolvimento. As publicações na área da educação, especialmente relacionadas a educação especial, reforçam a tendência em utilização da EDM na avaliação de crianças com deficiências, transtornos ou dificuldades de aprendizagem. Esses achados, associados aos descritores observados, apontam, como citado por Silva (2013) para uma preocupação da comunidade acadêmica em analisar essa temática. Espera-se que esses dados publicados possam apresentar o respaldo científico necessário para o favorecimento da constituição de programas de avaliação e intervenção que atinjam utilização diária de profissionais das áreas da saúde e educação.

Por fim, cabe ressaltar que, apesar da maior concentração de pesquisas realizadas nas regiões Sul e Sudeste do Brasil, a teia de conexões entre autores e Universidades aqui observada, assim como o desprendimento das publicações de seu autor original, mostram uma aceitação do campo acadêmico e científico quanto a EDM, fortalecendo a utilização de uma escala viável e condizente com a realidade brasileira.

\section{Referências}

ALANO, Valéria da Rosa et al. Aptidão física e motora em escolares com dificuldades na aprendizagem. Rev Bras Ciência e Mov, v.19, n.3, p.69-75, 2011.

AMARO, Kassandra Nunes et al. Validação das baterias de testes de motricidade global e equilíbrio da EDM. Rev Bras Ciência e Mov, v.17, n.2, 2009.

\section{AMERICAN PSYCHIATRIC ASSOCIATION - APA. DSM-5: Manual diagnóstico e estatístico de transtornos mentais. Artmed Editora, 2013.}

ANDRADE, Alexandro; DOMINSKI, Fábio Hech; COIMBRA, Danilo Reis. Scientific production on indoor air quality of environments used for physical exercise and sports practice: bibliometric analysis. J environ manag, v.196, p.188-200, 2017. 
ANJOS, Isabelle de Vasconcellos Corrêa dos; FERRARO, Alexandre Archanjo. A influência da dança educativa no desenvolvimento motor de crianças. Rev Paul de Pediat, v.36, n.3, p.337-344, 2018.

ARNONI, Joice Luiza Bruno et al. Effects of active videogame-based intervention on selfconcept, balance, motor performance and adaptive success of children with cerebral palsy: preliminary study. Fisiot e Pesq, v.25, n.3, p.294-303, 2018.

BARBOSA, Gardenia de Oliveira; MUNSTER, Mey de Abreu van. O efeito de um programa de equoterapia no desenvolvimento psicomotor de crianças com indicativos de transtorno de déficit de atenção e hiperatividade. Rev Bras Edu Esp, v.20, n.1, p.69-84, 2014.

BRAMNESS, Jorgen G. et al. A bibliometric analysis of European versus USA research in the field of addiction. Research on alcohol, narcotics, prescription drug abuse, tobacco and steroids 2001-2011. Eur Addict Res, v.20, n.1, p.16-22, 2014.

CAETANO, Maria Joana Duarte; SILVEIRA, Carolina Rodrigues Alves; GOBBI, Lilian Teresa Bucken. Desenvolvimento motor de pré-escolares no intervalo de 13 meses. Rev Bras Cineant Desemp Hum, v.7, n.2, p.05-13, 2005.

CAMARGOS, Ana Cristina Resende et al. Desenvolvimento motor de crianças pré-termo moderadas aos sete e oito anos de idade. Fisiot Pesq, v.18, n.2, p.182-187, 2011.

CAMPOS, Sara Domiciano Franco de et al. O brincar para o desenvolvimento do esquema corporal, orientação espacial e temporal: análise de uma intervenção. Cad Bras Terap Ocup, v.25, n.2, p.275-285, 2017.

CAON, Giane; RIES, Lilian Gerdi Kittel. Triagem do desenvolvimento motor nos dois primeiros anos de vida. Pediat Mod, v.39, n.7, p.11-17, 2003.

CARDEAL, Cintia Mota et al. Efeito de um programa escolar de estimulação motora sobre desempenho da função executiva e atenção em crianças. Motric, v.9, n.3, p.44-56, 2013.

COORDENAÇÃO DE APERFEIÇOAMENTO DE PESSOAL DE NÍVEL SUPERIOR CAPES [homepage da internet]. Resultado da avaliação quadrienal 2017-2 [acesso em 25 de abril de 2019]. Disponível em: http://avaliacaoquadrienal.capes.gov.br/resultado-daavaliacao-quadrienal-2017-2.

CRIPPA, Liamara Regina et al. Avaliação motora de pré-escolares que praticam atividades recreativas. Rev Educ Fís, v.14, n.2, p.13-20, 2003.

CRUZ, Mayara Moura Alves da et al. Perfil do desenvolvimento motor em escolares com excesso de peso. ABCS Health Scienc, v.42, n.3, 2017.

DEITZ, Jean Crosetto; KARTIN, Deborah; KOPP, Kay. Review of the Bruininks-Oseretsky test of motor proficiency, (BOT-2). Phys occup therapy ped, v.27, n.4, p.87-102, 2007. 
DEL AGOSTINI, Franciele. O desenvolvimento da motricidade global em crianças de 6 e 7 anos a partir dos jogos pré-desportivos coletivos. Rev Bras Fs Fut, v.7, n.27, p.554-562, 2015.

Descritores em Ciências da Saúde: DeCS. São Paulo: BIREME / OPAS / OMS, 2017. Disponível em: http://decs.bvsalud.org. Acesso em 15 de set. 2020.

FERNANI, Deborah Cristina Gonçalves Luiz et al. Motor intervention in children with school learning difficulties. J Human Grow Develop, v.23, n.2, p.209-214, 2013.

FONSECA, Fernando Richardi da; BELTRAME, Thaís Silva; TKAC, Claudio Marcelo. Relação entre o nível de desenvolvimento motor e variáveis do contexto de desenvolvimento de crianças. J Phys Edu, v.19, n.2, p.183-194, 2008.

GOULARDINS, Juliana Barbosa et al. Motor profile of children with attention deficit hyperactivity disorder, combined type. Res Develop Disab, v.34, n.1, p.40-45, 2013.

GOULARDINS, Juliana Barbosa; MARQUES, Juliana Cristina Fernandes Bilhar; CASELLA, Erasmo Barbante. Quality of life and psychomotor profile of children with attention deficit hyperactivity disorder (ADHD). Arq Neuro-Psiq, v.69, n.4, p.630-635, 2011.

HENDERSON, Sheila E; SUGDEN, David A; BARNETT, Anna L. Movement assessment battery for children - 2nd ed. London: The Psychological Corporation; 2007.

HU, Hui et al. Ambient air pollution and hypertensive disorders of pregnancy: a systematic review and meta-analysis. Atmos Environ, v.97, p.336-345, 2014.

IWABE, Cristina; FREZZATO, Renata Camargo; NOGUEIRA, Ana Lívia. Motor outcome in a patient with mucopolysaccharidosis type 1. Rev Paul Pediat, v.28, n.3, p.372-375, 2010.

LAMÔNICA, Dionísia Aparecida Cusin; PICOLINI, Mirela Machado. Habilidades do desenvolvimento de prematuros. Revista CEFAC, v. 11, p.145-153, 2009.

LAUX, Rafael Cunha; OLIVEIRA, Sandra Rogéria de; CORAZZA, Sara Teresinha. Intervenção psicomotora em crianças disgráficas. Dist Comun, v.28, n.4, 2016.

LORENZO, Suelen Moraes de; BRACCIALLI, Lígia Maria Presumido; ARAÚJO, Rita de Cássia Tibério. Realidade virtual como intervenção na síndrome de Down: uma perspectiva de ação na interface saúde e educação. Rev Bras Edu Esp, v.21, n.2, p.259274, 2015.

MANSUR, Samira Schultz; MARCON, Adair José. Perfil motor de crianças e adolescentes com deficiência mental moderada. J Hum Grow Develop, v.16, n.3, p.9-15, 2006.

MARONESI, Leticia Carrillo et al. Analysis of an intervention directed to the development of balance and gross and fine motor coordination. Cad Bras Ter Ocup, v.23, n.2, p.273284, 2015. 
MATSUNAGA, Natasha Yumi et al. Efeitos de atividades psicomotoras no desenvolvimento motor de pré-escolares de cinco anos de idade. ConSc Saúde, v.15, n.1, 2016.

MEDINA, Josiane; ROSA, Greisy Kelli Broio; MARQUES, Inara. Desenvolvimento da organização temporal de crianças com dificuldades de aprendizagem. Journal of Physical Education, v.17, n.1, p.107-116, 2006.

MEDINA-PAPST, Josiane; MARQUES, Inara. Avaliação do desenvolvimento motor de crianças com dificuldades de aprendizagem. Rev Bras Cineant Desemp Hum, v.12, n.1, p.36-42, 2010.

OKUDA, Paola Matiko Martins et al. Coordenação motora fina de escolares com dislexia e transtorno do déficit de atenção e hiperatividade. Rev Cefac, p.876-885, 2011.

OKUDA, Paola Matiko Martins. Caracterização do perfil motor de escolares com transtorno autístico. Rev Edu Esp, v.23, n.38, p.443-454, 2010.

PAVÃO, Silvia Leticia et al. Impact of a virtual reality-based intervention on motor performance and balance of a child with cerebral palsy: a case study. Rev Paul Ped, v.32, n.4, p.389-394, 2014.

PIPER, Martha C.; DARRAH, Johanna. Motor assessment of the developing infant. Pennsylvania: WB Saunders Company, 1994.

POETA, Lisiane Schilling et al. Desenvolvimento motor de crianças obesas. R Bras Cienc Mov, v.18, n.4, p.18-25, 2011.

POETA, Lisiane Schilling; ROSA NETO, Francisco. Motor assessment in school-aged children with indicators of the attention deficit/hyperactivity disorder. Rev Neur, v.44, n.3, p.146-149, 2007.

PRESTES, Daniela Bosquerolli; WEISS, Silvio; ARAÚJO, Julio César Oliveira. A equoterapia no desenvolvimento motor e autopercepção de escolares com dificuldade de aprendizagem. Ciênc Cogn, v.15, n.3, 2010.

ROCHA, Priscila Garcia Marques da; ROCHA, Darley José Olimpio da; BERTOLASCE, André Luiz. A influência da iniciação ao treinamento esportivo sobre o desenvolvimento motor na infância: um estudo de caso. J Phys Edu, v.21, n.3, p.469-477, 2010.

RONDON, Tatiane Aparecida et al. Atividades rítmicas e Educação Física escolar: possíveis contribuições ao desenvolvimento motor de escolares de 08 anos de idade. Motriz, v.16, n.1, p.124-134, 2010.

ROSA NETO, Francisco et al. A lateralidade cruzada e o desempenho da leitura e escrita em escolares. Rev Cefac, v.15, n.4, 2013.

ROSA NETO, Francisco et al. Análise da consistência interna dos testes de motricidade fina da EDM: Escala de Desenvolvimento Motor. J Phys Educ, v.21, n.2, p.191-197, 2010a. 
ROSA NETO, Francisco et al. Desenvolvimento motor de crianças com indicadores de dificuldades na aprendizagem escolar. Rev Bras Ciênc Mov, v.15, n.1, p.45-52, 2007.

ROSA NETO, Francisco et al. Importância da avaliação motora em escolares: análise da confiabilidade da Escala de Desenvolvimento Motor. Rev Bras Cineant Desemp Hum, v.12, n.6, p.422-427, $2010 \mathrm{~b}$.

ROSA NETO, Francisco et al. Motor development of children with attention deficit hyperactivity disorder. Rev Bras Psiq, v.37, n.3, p.228-234, 2015.

ROSA NETO, Francisco et al. O esquema corporal de crianças com dificuldade de aprendizagem. Psicol Esc Edu, v.15, n.1, p.15-22, 2011.

ROSA NETO, Francisco. Manual de Evaluación Motora - EDM III. 3a ${ }^{a}$. ed. Florianópolis: Udesc, 2018a.

ROSA NETO, Francisco. Manual de Intervenção Motora: educação infantil, ensino fundamental e educação especial. Florianópolis: Dioesc; 2015.

ROSA NETO, Francisco. Manual de Intervenção Motora: educação infantil, ensino fundamental e educação especial. Porto Alegre: Artmed; 2002.

ROSA NETO, Francisco. Manual of Motor Function Assessment - EDM III. $3^{\text {a }}$. ed. Florianópolis: Udesc, 2018b.

ROSA NETO, Francisco.; BIANCO, Claudia. Dispraxias: Identificação Precoce nos Transtornos de Desenvolvimento e Aprendizagem na Educação Infantil. Movimenta, v.11, p.349-356, 2018.

ROSA, Greisy Kelli Broio et al. Desenvolvimento motor de criança com paralisia cerebral: avaliação e intervenção. Rev Bras Edu Esp, p.163-176, 2008.

SANTOS, Ana Paula Maurilia dos et al. Aspectos biopsicossociais em escolares com atraso no desenvolvimento motor: um estudo longitudinal. J Hum Grow Develop, v.26, n.1, p.112-118, 2016.

SANTOS, Ana Paula Maurília dos et al. Efeitos da intervenção motora em uma criança com síndrome de Williams. Rev Bras Edu Esp, v.21, n.3, p.423-432, 2015.

SANTOS, Ana Paula Maurília dos; ROSA NETO, Francisco; PIMENTA, Ricardo de Almeida. Avaliação das habilidades motoras de crianças participantes de projetos sociais/esportivos. Motric, v.9, n.2, p.51-61, 2013.

SANTOS, Ana Paula Maurilia dos; WEISS, Silvio Luiz Indrusiak; ALMEIDA, Geciely Munaretto Fogaça. Avaliação e intervenção no desenvolvimento motor de uma criança com Síndrome de Down. Rev Bras Edu Esp, v.16, n.1, p.19-30, 2010. 
SANTOS, Camila Ramos dos et al. Efeito da atividade esportiva sistematizada sobre 0 desenvolvimento motor de crianças de sete a 10 anos. Rev Bras Edu Fís Esp, v.29, n.3, p.497-506, 2015.

SANTOS, Luciano Bucco dos; GONZÁLEZ, Marta Zubiaur. Analysis of the motor development in brazilian schoolchildren with corporal measures of obesity and overweight. Rev Intern Med Cienc Activid Fis Dep, v.15, n.59, p.593-611, 2015a.

SANTOS, Luciano Bucco dos; GONZÁLEZ, Marta Zubiaur. Estudio del desempeño motor en niños leoneses que practican actividades deportivas extraescolares. Rev Cien Dep, v.11, n.2, p.167-176, 2015b.

SClmago. SJR. SCImago Journal \& Country Rank. [s.d.] Disponível em: http://www.scimagojr.com. Acesso em 25 de abr. 2019.

SILVA, Adriano Zanardi da et al. Intervenção psicomotora para estímulo do desenvolvimento motor de escolares de 8 a 10 anos. Rev Bras Cineant Desemp Hum, v.19, n.2, p.150-163, 2017.

SILVA, Aliny Pereira da. Vulnerabilidade de risco para o desenvolvimento motor: prevalência de dispraxias na educação infantil. 2017. 86 f. Dissertação (Mestrado em Ciências do Movimento Humano) - Universidade do Estado de Santa Catarina, Florianópolis, 2017.

SILVA, Joyce Karla Machado et al. Desenvolvimento motor de crianças nascidas prétermo e a termo na fase motora fundamental: um estudo transversal. Fisiot mov, v.29, n.3, p.581-588, 2016.

SILVA, Maria Natalia Santos da; DOUNIS, Alessandra Bonorandi. Motor development profile in 9-11 year-old children from the municipal education system of Maceio, Alagoas State, presenting low school performance. Cad Terap Ocup, v.22, n.1, p.63-70, 2014.

SILVA, Rosemary Cristina. Avaliação da informação científica em Bibliometria aplicada às Ciências da Saúde. In: ANAIS DO CONGRESSO BRASILEIRO DE BIBLIOTECONOMIA, DOCUMENTAÇÃO E CIÊNCIA DA INFORMAÇÃO-FEBAB. 2013. p. 3324-3339.

SILVEIRA, Carolina Rodrigues Alves et al. Validade de construção em testes de equilíbrio: ordenação cronológica na apresentação das tarefas. Rev Bras Cineant Desemp Hum, v.8, n.3, p.66-72, 2006.

SOARES, Daniela Bento et al. Influence of the physical activity on motor performance of children with learning difficulties. Rev Cefac, v.17, n.4, p.1132-1142, 2015.

SUZUKI, Simone; GUGELMIM, Márcia Regina Garcia; SOARES, Antonio Vinicius. O equilíbrio estático em crianças em idade escolar com transtorno de déficit de atenção/hiperatividade. Fisiot Mov, v.18, n.3, 2005. 
TORQUATO, Jamili Anbar et al. A aquisição da motricidade em crianças portadoras de Síndrome de Down que realizam fisioterapia ou praticam equoterapia. Fisiot Mov, v.26, n.3, p.515-525, 2013.

TRINDADE, André Soares; NASCIMENTO, Marcos Antonio. Avaliação do Desenvolvimento Motor em Crianças com Síndrome de Down. Rev Bras Edu Esp, v.22, n.4, p.577-588, 2016.

VALENTINI, Nadia Cristina et al. Prevalência de déficits motores e desordem coordenativa desenvolvimental em crianças da região Sul do Brasil. Revista Paulista de Pediatria, v.30, n.3, p.377-384, 2012.

VIEIRA, Martina Estevam Brom; RIBEIRO, Fabiane; FORMIGA, Cibelle Kayenne Martins Roberto. Principais instrumentos de avaliação de desenvolvimento da criança de zero a dois anos de idade. Revista Movimenta, v.2, n.1, 2009.

\section{Correspondência}

Ricardo de Almeida Pimenta - Universidade Federal Rural do Rio de Janeiro, Instituto de Educação, Departamento de Educação Física e Desporto, Rodovia BR - 465 Km7, Seropédica, Rio de Janeiro - Brasil.

CEP: $23897-000$

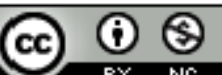

EY TC This work is licensed under a Creative Commons Attribution-NonCommercial 4.0 International (CC BY-NC 4.0) 